\title{
Review
}

\section{Key structures of bacterial peptidoglycan and lipopolysaccharide triggering the innate immune system of higher animals: Chemical synthesis and functional studies}

\author{
By Shoichi Kusumoto, ${ }^{* 1, \dagger}$ Koichi FukASE*2 and Tetsuo SHIBA ${ }^{* 3}$ \\ (Communicated by Satoshi ŌMURA, M.J.A.)
}

\begin{abstract}
Chemistry-based investigation is reviewed which led to identification of the active entities responsible for the immunostimulating potencies of peptidoglycan and lipopolysaccharide. Though these glycoconjugates which ubiquitously occur in wide range of bacteria as the essential components of their cell envelopes have long been known to enhance the immunological responses of higher animals, neither the precise chemical structures required nor the mechanism of their action remained to be elucidated until early 1970s. Chemical synthesis of partial structures of peptidoglycan proved $N$-acetylmuramyl-L-alanyl-D-isoglutamine to be the minimum structure responsible for the activity and led to later identification of its receptor protein Nod2 present in animal cells. Another active partial structure of peptidoglycan, $\gamma$-D-glutamylmeso-diaminopimelic acid, and its receptor Nod1 were also identified as well. With regard to lipopolysaccharide, its glycolipid part named lipid A was purified and the structure studied. Chemically synthesized lipid A according to the newly elucidated structure exhibited full activity described for lipopolysaccharide known as endotoxin. Synthetic homogeneous lipid A and its structural analogues and labeled derivatives enabled precise studies of their interaction with receptor proteins and the mechanism of their action. Chemical synthesis of homogeneous partial structures of peptidoglycan and lipopolysaccharide gave unequivocal evidences for the concept that definite small molecular parts of these complex macromolecular bacterial glycoconjugates are specifically recognized by their respective receptors and trigger our defense system now widely recognized as innate immunity.
\end{abstract}

Keywords: chemical synthesis, muramyl peptides, lipid A, peptidoglycan, lipopolysaccharide, innate immunity

\section{Introduction}

Bacterial cells and some of their typical components have long been known to enhance the immunological response of higher animals. When simultaneously applied with antigenic proteins to experimental animals, heat-killed Mycobacterium cells, for example, strongly enhances the production of

*1 Suntory Institute for Bioorganic Research, Osaka, Japan.

*2 Department of Chemistry, Graduate School of Science, Osaka University, Osaka, Japan.

*3 Protein Research Foundation, Osaka, Japan.

$\dagger$ Correspondence should be addressed: S. Kusumoto, Suntory Institute for Bioorganic Research, Wakayamadai 1-1-1, Shimamotocho, Mishima-gun, Osaka 618-8503, Japan (e-mail: skus@sunbor. or.jp). specific antibodies against the relevant antigens. ${ }^{1)}$ Endotoxin of Gram-negative bacteria was also known as one of the most potent immunostimulants. ${ }^{2)}$ Intensive studies have been carried out by microbiologists, biochemists, and immunologists to understand the details of these highly interesting phenomena and their molecular mechanism. Until early 1970s, two typical bacterial glycoconjugates, i.e., peptidoglycan (PGN) and lipopolysaccharide (LPS), the latter being the active entity of endotoxin, were shown to be major active cell components responsible for the immunostimulative function attributed to bacterial cells. ${ }^{2), 3)} \mathrm{PGN}$ is a vital cell wall component shared by all types of bacteria, while LPS is an essential structural element of the outer membrane present in all Gram-negative bacterial cells. No information was, 
however, available of their active structures because of the complex and heterogeneous structures of these bacterial high molecular weight glycoconjugates. In view of such situation, we anticipated the existence of a general defense mechanism of higher animals, where ubiquitous, typical bacterial cell components essential for their survival are recognized as alarm signals of infection and trigger the host system against invading microbes. We thus started our chemical investigation toward characterization of the key structures responsible for the important functions of these bacterial glycoconjugates. By the aid of our chemical syntheses, we succeeded in unequivocal determination of the definite structures essential for the immunostimulating actions of both PGN and LPS in collaboration with many research groups world wide.

Later discovery of the Toll-like receptor (TLR) family at the end of the twentieth century led to unveiling the system of innate immunity, which takes the major part of the first line defense of higher animals against bacteria, viruses and other invading microbes before the more effective and well-known acquired immunity system based on the specific antigen/antibody recognition comes into action. $\left.{ }^{4}\right)$ Our chemistry-based approach in collaboration with bioscientists further led us to elucidation of the detailed mechanism of recognition of these bacterial components as representative initial players in the innate immune systems.

\section{Muramyl peptides as the immunostimulative principle of bacterial peptidoglycan}

The early observation by Freund that Mycobacterium cells induces the systemic activation of immunological responses of higher animals ${ }^{1)}$ prompted further investigations which led to the conclusion that such activation is not restricted to Mycobacteria alone but other common bacterial cells also exhibit the same ability as well. This ability was referred to as immunoadjuvant activity or more simply adjuvant activity. More importantly, PGN shared by all bacterial cells was then proposed to be responsible for the activity. PGN is ubiquitously distributed both in Gram-positive and -negative bacterial cells as the major and vital component of their cell envelope and protects the life process in the cells from mechanical, osmotic and other stresses from outside. Chemically, PGN has a three dimensional stable network structure composed of $\beta(1-4)$ glycan main chains and peptide bridges. ${ }^{5), 6)}$ The latter interlinks the former glycan chains of alternating $\mathrm{N}$-acetyl-Dglucosamine (2-acetamdio-2-deoxy-D-glucose, GlcNAc) and $N$-acetylmuramic acid (MurNAc). Further investigation by French and Japanese research groups showed that disaccharide (GlcNAc-MurNAc)-oligopeptide fractions obtained by limited enzymatic digestion of PGN exhibited definite effects of immunostimulation. However, neither isolation nor characterization of the smallest definite structure responsible for the function was possible because of the limited amount of the starting natural PGN and extreme difficulty in the isolation of homogeneous partial hydrolysis products.

In early 1970s we joined this research field and started chemical synthesis of several $N$-acetylmuramyl (MurNAc) peptides corresponding to the proposed partial structure of the lysine-type PGN (Fig. 1).7),8) Among the compounds synthesized (Fig. 2), MurNAcL-alanyl-D-isoglutamine (muramyl dipeptide, MDP, 1) and MurNAc-tri- and -tetrapeptides (2 and 3) enhanced immune responses of guinea pigs against a given protein antigen in manners similar to those of natural peptidoglycan preparations as tested in standard in vivo test systems used that time. ${ }^{7)}$ By contrast, neither MurNAc-L-alanine nor the tetrapeptide devoid of the MurNAc moiety showed such activity. French research group also concluded MDP (1) as the minimum adjuvant active structure even slightly earlier than us but we were completely independent. ${ }^{9), 10)}$

These were a direct evidence that the adjuvant activity of natural macromolecular PGN to enhance the general immunological responses of higher animals can be reproduced by a synthetic definite molecule of MDP whose molecular weight is only as low as 538. This clear conclusion was first drawn by the use of homogeneous synthetic preparations free from any contaminants of bacterial origin.

In view of the strict structural requirement for the adjuvant activity observed with various structural analogues of MDP, ${ }^{3), 11), 12)}$ the presence of its specific receptor in/on host animal cells was expected. In spite of various efforts, however, we have to wait almost thirty years, until the receptor for MDP was identified as described below. For example, we synthesized ${ }^{14} \mathrm{C}$-labeled MDP as a probe to detect its binding proteins, ${ }^{13}$ ) but investigations with this labeled compound did not give any satisfactory result.

With regards to the peptide chain, the dipeptide linked to the MurNAc residue is sufficient for the full 


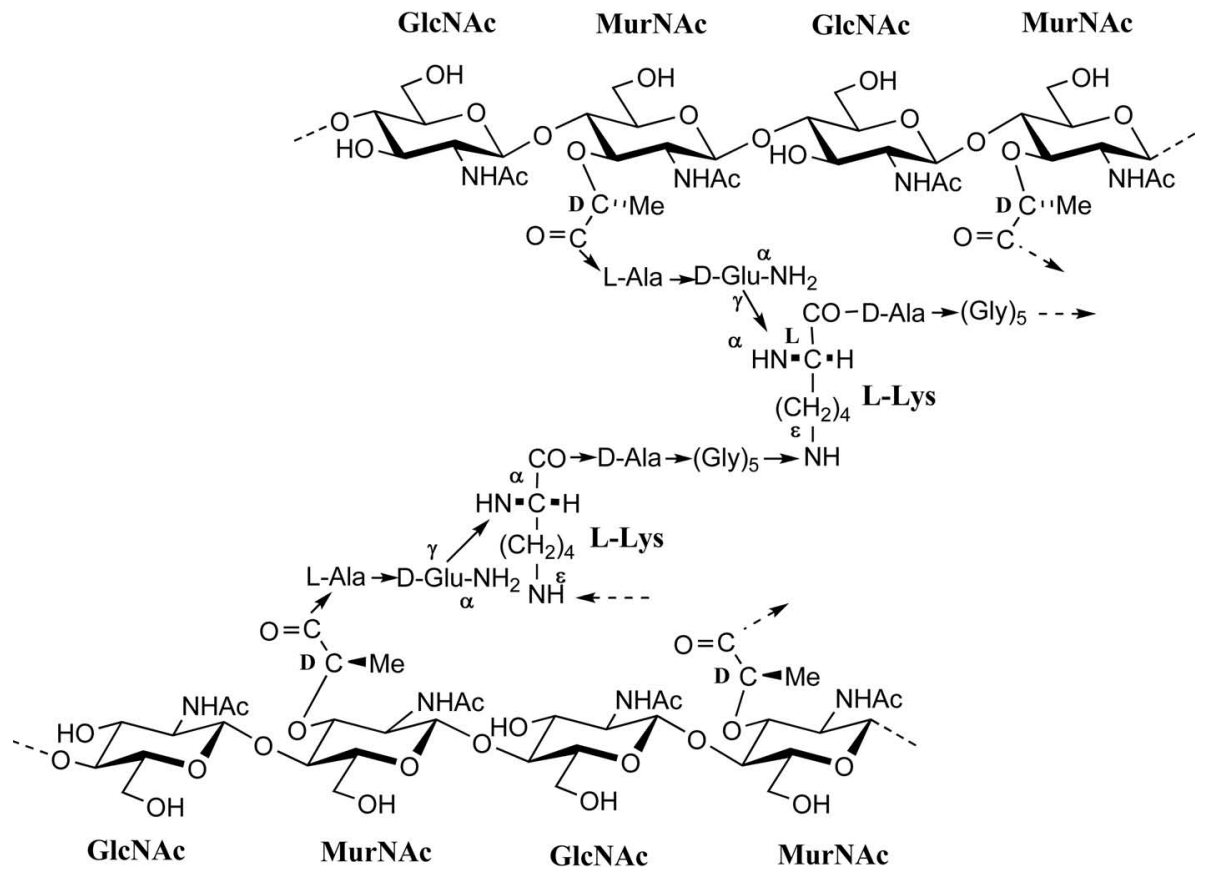

Fig. 1. Schematic representation of peptidoglycan of Staphylococcus aureus.

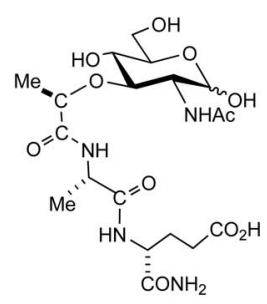

1

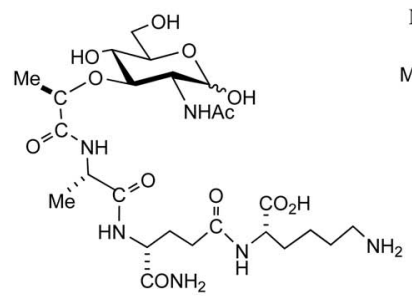

2

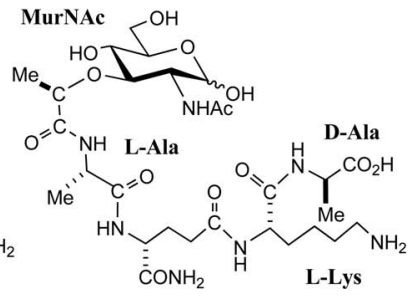

D-isoGln 3

Fig. 2. Structures of $N$-acetylmuramyl dipeptide (1), tripeptide (2), and tetrapeptide (3) chemically synthesized.

activity, no distinct difference being observed among the potency of MurNAc-di-, -tri-, and -tetrapeptides. ${ }^{7)}$ Our early synthesis of a disaccharide, GlcNAcMurNAc, indicated that its dipeptides conjugate has more potent immunostimulating activity than MDP. ${ }^{14), 15)}$ In order to systematically examine the effect of the glycan chain length on the activity, we synthesized repeating $\beta(1-4)$ oligosaccharides of alternating GlcNAc and MurNAc residues corresponding to the common backbone structure of bacterial PGN. ${ }^{16}$

Synthesis was achieved by iteration of a reaction series of glycosyl activation, coupling and deprotection for the formation of a sequence of di-, tetra-, and octasaccharides as illustrated in Fig. 3. Thus,
N-2,2,2-trichloroethoxycarbonylated (Troc) 2,2,2trichloroacetimidates were used as glycosyl donors which was expected to assure efficient and selective formation of $\beta$-glycosidic linkage of 2-amino-2-deoxy sugars. Coupling of 4,6-O-benzylidene- $N$-Troc imidate (4) with an $N$-Troc-muramic acid acceptor (5), in fact, afforded desired protected $\beta(1-4)$ disaccharide (6) in an excellent yield. A part of the disaccharide (6) was converted to a disaccharide donor (7), whereas the other part of the same 6 gave a disaccharide acceptor (8) by regioselective reductive opening of the benzylidene ring. Coupling of the two components gave a repeating tetrasaccharide (9), which was again converted to both tetrasaccharide donor and acceptor for the preparation of octasac- 


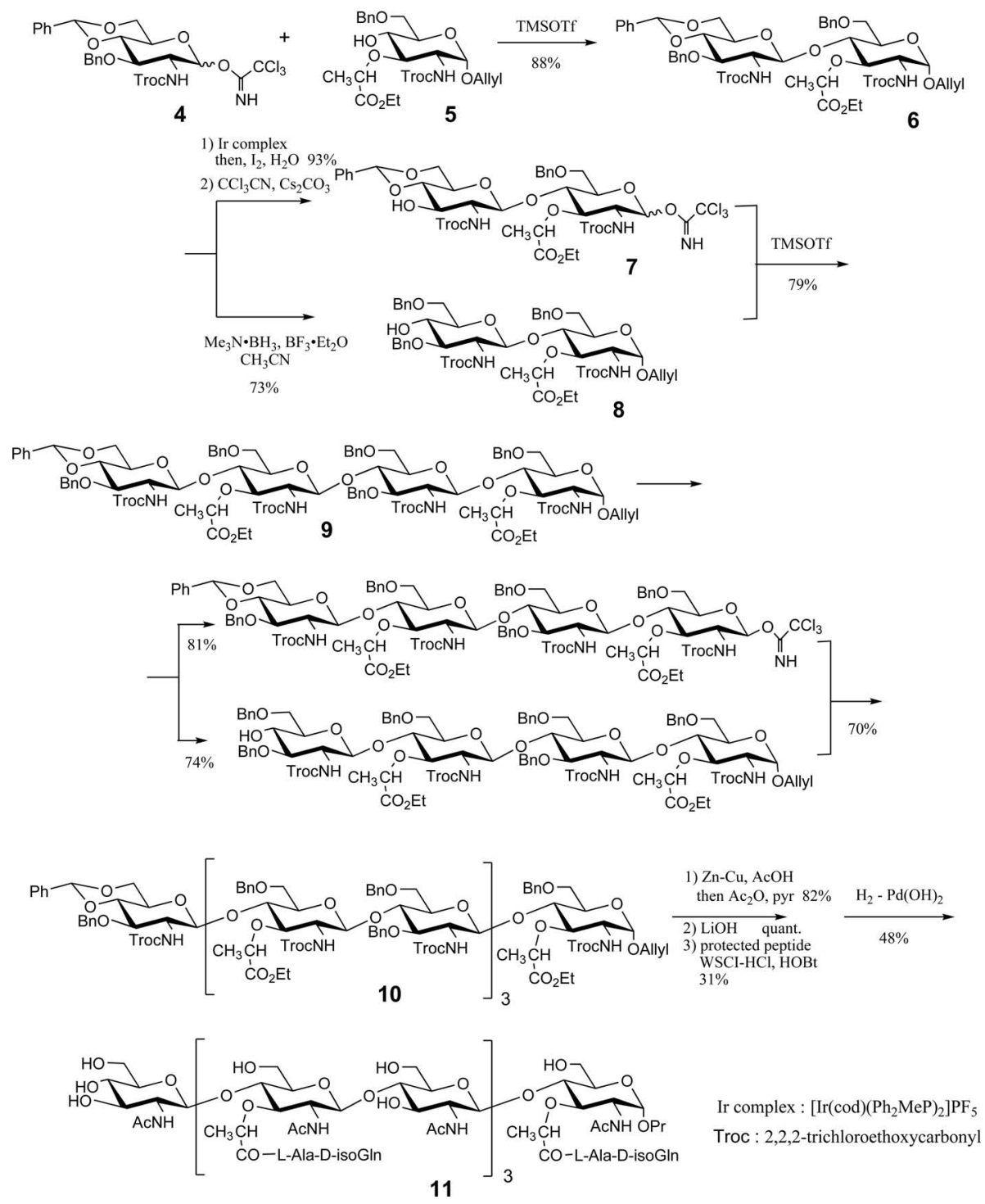

Fig. 3. Synthetic scheme for a repeating octasaccharide linked to four dipeptides (11).

charide (10). Removal of all the $N$-Troc protecting groups followed by $\mathrm{N}$-acetylation, ester hydrolysis, and coupling with a dipeptide component at every MurNAc residue, and final hydrogenolytic deprotection afforded the largest partial structure of PGN 11 ever obtained synthetically. The corresponding tetrasaccharide and disaccharide with the dipeptide linked to each MurNAc residue were also prepared from $\mathbf{9}$, and 6 , respectively. ${ }^{16), 17)}$

All the above synthetic PGN fragments showed definite immunostimulating activities similar to that of MDP. When their tumor necrosis factor- $\alpha$ (TNF$\alpha$ )-inducing potencies were quantitatively compared by the aid of enzyme-linked immunosorbent assay (ELISA), MDP proved to be most active and the potency decreased as the glycan chain becomes longer from di-, tetra- to octasaccharides. This was contrary to our expectation drawn from the early experiments with soluble PGN. ${ }^{18)}$ Our result obtained with the synthetic definite molecules corresponding to larger PGN fragments was confirmed soon by using the receptor protein Nod2 described below: MDP activates the signaling system more efficiently than its oligosaccharide derivatives. ${ }^{17)}$ Our present understanding should therefore be that the soluble PGN might activate animal cells not directly through Nod2 (see 
below) or the soluble PGN preparation used contained yet unknown other active components of bacterial origin.

Inohara et al. and another group identified in the meantime two cytoplasmic proteins named Nod1 and Nod2 which belong to the family of Nod-LRR proteins. Of the two, Nod2 was concluded to be a specific receptor for MDP, which has been looked for 30 years after the discovery of MDP as the minimal adjuvant active structure of PGN. ${ }^{19)}$ Nod1 was also concluded by the use of our synthetic specimen to be a receptor for a dipeptide, $\gamma$-D-glutamyl-mesodiaminopimelic acid, which is another minimal active structure of meso-diaminopimelic acid (meso-DAP)type PGN. ${ }^{20), 21)}$ This type of PGN, which occurs in the cell envelope of most of Gram-negative bacteria and Gram-positive bacilli, contains meso-DAP in place of L-lysine in the above described Lys-type PGN (Fig. 1). ${ }^{6,22)}$ On recognition of their respective ligands, these receptors trigger the intracellular signaling cascade to start the innate immune defense system against invading bacteria. Our synthetic specimens contributed to the unequivocal identification of the ligands of both Nod1 and Nod2. The mechanism of the cell activation after the ligand recognition is being investigated in more details. ${ }^{23)}$

More recently various peptidoglycan fragments were found to be secreted from growing bacterial cells into the medium. ${ }^{24)}$ Contact with such environmental bacterial fragments in daily life is expected to play certain roles in developing the innate immune system of infants.

\section{Lipid A as the endotoxic active principle of lipopolysaccharide}

Characterization of the active principle of lipopolysaccharide (LPS), a typical cell surface component of Gram-negative bacteria, became the next main target of our research after identification of MDP. LPS was first described under the name of endotoxin in 1892 by Pfeiffer as a highly toxic component firmly bound to cells of Vibrio cholerae which is a causal bacterium of cholera. ${ }^{25)}$ Later all Gramnegative bacterial cells were found to contain endotoxin irrespective of their pathogenicity. Westphal and Lüderitz elaborated an efficient aqueous phenol extraction procedure of LPS from cells and showed protein-free LPS exhibits all endotoxic activities. ${ }^{26)}$ LPS induces high fever, septic shock and in serious cases even death of experimental animals. Similar

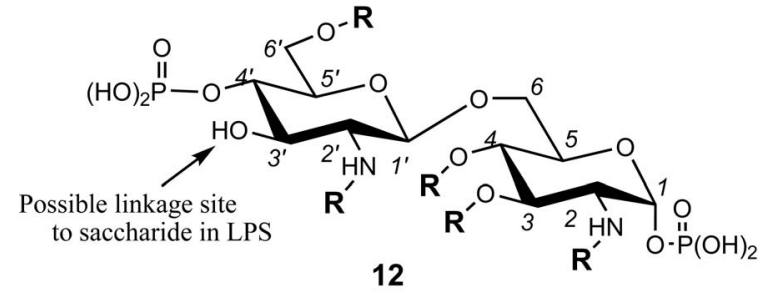

$\mathbf{R}$ : long chain acyl group or $\mathrm{H}$

Fig. 4. Old proposed structure of Salmonella lipid A.

effects were observed with human, so that LPS has been causing serious clinical problems even at present. LPS has attracted interests of researchers because it exhibits, in addition to these detrimental activities, beneficial functions to activate immunological system of higher animals, for example, potent antitumor activity being known for it.

LPS is a common and characteristic component of the cell surface architecture of Gram-negative bacteria, constituting the outer leaflet of the lipid bilayer called outer membrane located outside the PGN layer of the cells. Chemically, LPS consists of covalently bound three distinct parts, namely, O-antigenic polysaccharide, core oligosaccharide, and glycolipid. Westphal and Lüderitz then reported selective cleavage of the linkage between the latter two parts by mild acid hydrolysis and found the glycolipid, which they named "lipid A", retains full endotoxic activity. ${ }^{27)}$ The chemical structure of lipid A was intensively studied by their group.

Lipid A is an amphiphilc molecule consisting of covalently bound hydrophilic part of phosphorylated carbohydrate and lipophilic long chain fatty acyl groups. Preparations of lipid A from bacterial cells are always mixtures of molecular species with different number and/or locations of acyl groups. Its strong tendency to aggregate made purification of lipid A quite difficult in earlier times so that homogeneous molecular species of lipid A had never been available. The structure of lipid A from Salmonella minnesota was deduced as $\mathbf{1 2}$ (Fig. 4) for such a mixture. According to the proposal, a glucosamine $\beta(1-6)$ disaccharide phosphorylated at the 1- and 4'-positions represents the hydrophilic backbone, which is acylated at the two amino and 3-, 4-, and 6'-hydroxy groups. ${ }^{28), 29)}$ The 3'-hydroxy group was thought to be the linkage position of the core oligosaccharide and therefore expected to remain not modified in 

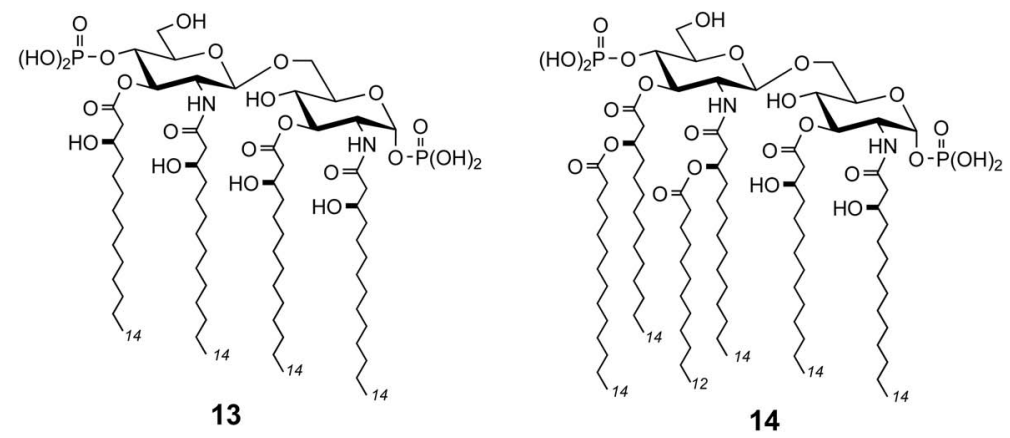

Fig. 5. The chemical structures of a tetraacylated biosynthetic precursor of lipid A (13) and E. coli lipid A (14).

lipid A liberated by mild acid hydrolysis from the saccharide part. Most of the fatty acid components were of 3-hydroxylated saturated types with straight carbon chains. Among them, $(R)$-3-hydroxylated tetradecanoic acid was the major one. A certain proportion of nonhydroxylated acids were always present.

We started chemical synthesis of the proposed structure of lipid A to prove whether this particular molecule is responsible for the activity described for bacterial endotoxin. Since the exact positions of acylation in bacterial lipid A was not fixed until that time, our synthesis targeted at fully acylated structures using tetradecanoic (myristic) acid and (R)-3hydroxytetradecanoic acid as acyl components. Important keys for successful synthesis were: 1) preparation of optically pure 3-hydroxy fatty acids, 2) efficient formation of chemically labile glycosyl phosphates, 3) selective protection and deprotection of hydroxy groups. Synthetic lipid A analogues of the first generation were obtained by solving all these problems. ${ }^{30), 31)}$ Contrary to our expectation, the preparations unfortunately did not show any typical endotoxic activity. ${ }^{32)}$ This quite disappointing result must mean either the proposed structure of lipid A was incorrect or the concept was wrong that lipid $\mathrm{A}$ is the endotoxic entity of LPS. The possible most essential approach to characterize the endotoxic principle at that moment was determination of the exact molecular structure of lipid A including the architecture of the hydrophilic backbone as well as the distribution and chain lengths of fatty acyl groups.

To do this, a homogeneous molecular species has to be isolated: lipid A preparation from Escherichia coli Re mutant was selected as the substrate because this species was known to produce rather homogeneous lipid A. Selective removal of the chemically labile glycosyl phosphate of E. coli lipid A followed by methyl esterification gave a mixture, which was soluble in organic solvents and suitable for chromatographic purification. The major component of lipid A was thus isolated for the first time in a chemically pure form as a dimethyl ester of monophosphorylated derivative. Detailed high field NMR spectroscopic analysis of the purified specimen led to conclude that the previously proposed hydrophilic backbone structure is correct. The positions of direct acylation are the two amino and two hydroxy groups at the 3-, 3'-positions of the $\beta(1-6)$ glucosamine disaccharide. According to our composition analysis, the purified lipid A contains six fatty acids, i.e., four (R)-3-hydroxytetradecanoic acids and each one of dodecanoic and tetradecanoic acids. ${ }^{33)}$ Based on this information, the structure of a previously isolated biosynthetic precursor of lipid A, which contains only four 3-hydroxytetradecanoic acids, should hence be rationally proposed as $\mathbf{1 3}$. The complete structure of mature lipid A of E. coli Re mutant was then concluded as $\mathbf{1 4}$ through determination of the positions of the remaining two nonhydroxylated acids by selective chemical degradation and soft ionization MS analysis of the purified lipid A derivative: dodecanoic and tetradecanoic acids are site-specifically linked to the 3-hydroxy groups of $\mathrm{N}$ - and $\mathrm{O}$-bound hydroxytetradecanoic acid residues, respectively. ${ }^{34), 35)}$

Chemical synthesis of the newly elucidated structure of the biosynthetic precursor 13, designated precursor Ia and later renamed lipid IVa, was successfully achieved by combining similar procedures elaborated in our preceding works toward the "old" structures. ${ }^{36), 37)}$ The first chemical synthesis of the complete structure of mature E. coli type lipid A $\mathbf{1 4}$ immediately followed. ${ }^{34), 38)}$ Because of the unsymmetrical pattern of acylation on the two glucosamine 

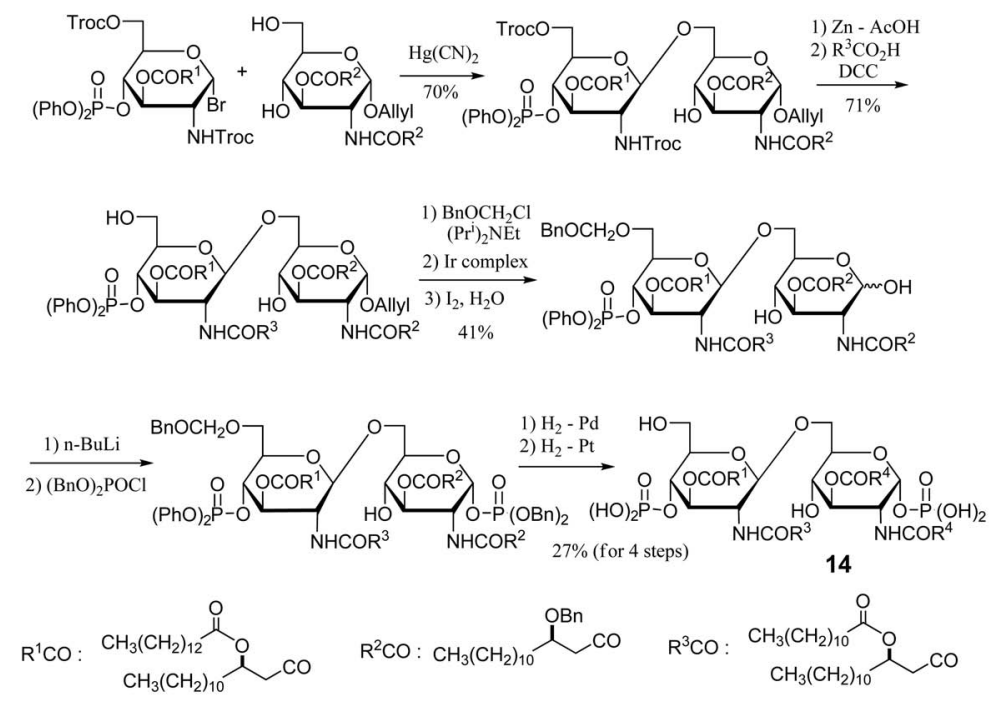

$\mathrm{R}^{4} \mathrm{CO}: \mathrm{CH}_{3}\left(\mathrm{CH}_{2}\right)_{10} \stackrel{\mathrm{OH}}{\mathrm{H}} \mathrm{Troc}:$ 2,2,2-trichloroethoxycarbonyl Ir complex : [ $\left.\operatorname{Ir}(\operatorname{cod})\left(\mathrm{PCH}_{3} \mathrm{Ph}_{2}\right)\right] \mathrm{PF}_{6}$

Fig. 6. The first chemical synthesis of E. coli lipid A (14).

residues, synthetic route to $\mathbf{1 4}$ had to be more complex than that for the symmetrically acylated $\mathbf{1 3}$. The following basic strategy was thus elaborated: 1) All persistent protecting groups were selected to enable mild hydrogenolytic removal at the final step. This should facilitate purification of the final amphiphilic product. 2) In order to reduce the number of protecting groups required, all the acyl groups and the protected 4'-phosphate were introduced at the stage of monosaccharide precursors. 3) Only the $N$ acyl group of the distal glucosamine residue was exceptionally introduced after the formation of the disaccharide. This was because $N$-3-acyloxyacyl groups on 2-amino sugar moieties were found to undergo $\beta$ elimination to form $\alpha, \beta$-unsaturated acyl derivatives when their glycosidic positions were activated for glycosylation reactions. The 2,2,2-trichloroethoxycarbonyl (Troc) group was used for the protection of this particular 2-amino group during glycosylation. This group was known to assist desired $\beta$-glycosilation by 2-amino-2-deoxy sugar moieties in good yields and could be selectively removed after the formation of the disaccharide in our previous work. ${ }^{30), 31)}$

4) The glycosyl phosphate moiety was introduced at the final synthetic stage just before the hydrogenolytic deprotection. This was a strategy to retain the chemically labile particular phosphate residue. Figure 6 illustrates the first synthesis of $\mathbf{1 4}$ according to this line.
The biological activities of the synthetic lipid A according to the revised structures (13 and $\mathbf{1 4})$ were immediately tested by our collaborating groups. ${ }^{39)-42)}$ The preparations showed definite endotoxic activity including both beneficial and detrimental ones described for natural lipid A of bacterial origin. The former 13, in particular, therefore represents the first synthetic compound which did reproduce the endotoxic responses in both in vivo and in vitro test systems. ${ }^{39), 40)}$ The latter 14 showed indistinguishable activity with a natural counterpart isolated from E. coli cells.41),42) The final and complete evidence was thus obtained in support of the concept that lipid A is the active entity of bacterial endotoxin almost hundred years after Pfeiffer had first described endotoxin in 1892. Long-concerned possible influence of any contaminants of bacterial origin was thereby completely excluded.

Successful chemical synthesis of lipid A not only meant the simple confirmation of its chemical structure but simultaneously had opened a new horizon in endotoxin research. Lipid A derivatives of any structures had become synthetically accessible in pure states. In the meantime many lipid A analogues were isolated from various bacteria and their structures elucidated. Some of the analogous structures were then synthesized, where synthetic procedures were improved in various aspects to attain higher efficiency and yields. As one of the representative ex- 

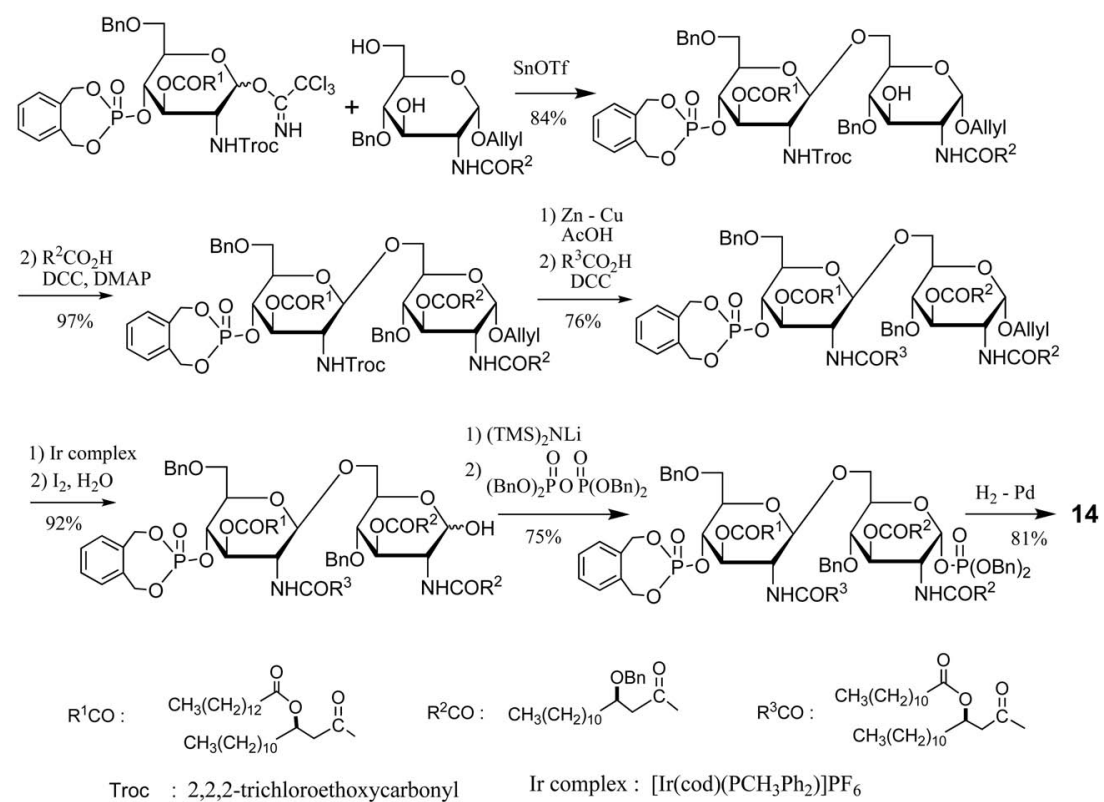

Fig. 7. Improved synthetic route to E. coli lipid A (14).

amples, improved synthetic route to the same $\mathbf{1 4}$ is shown in Fig. 7.43) By the use of many structural analogues synthesized, the relationship between chemical structures and biological activities were precisely studied on this group of glycolipid. ${ }^{44)-49)}$

A typical example where a striking effect of the structure was observed is an antagonistic function of the biosynthetic precursor 13. In our earlier work where the toxicity of preparations was determined by in vivo test on mice, both tetraacylated $\mathbf{1 3}$ and hexaacylated 14 exhibited potent positive activity. When they were tested by an in vitro human cellline system, the former showed no capacity to induce inflammatory cytokines such as TNF- $\alpha$ and interleukin-6 (IL-6) but even inhibits their induction by LPS. ${ }^{50), 51)}$ This was discovery of an antagonistic compound which inhibits the action of LPS or its active principle lipid A on human cells. New possibilities became realistic to find antagonistic compounds to be used clinically to suppress the toxic effects of LPS. Additional examples of antagonistic lipid A were then discovered from other bacterial species by other research groups, ${ }^{52), 53)}$ which led to chemical synthesis of artificial antagonistic molecules to be of possible value in clinical application against bacterial sepsis. $^{54), 55)}$

Chemical synthesis allows creation of artificial molecules never available from natural sources. Vari- ous natural and unnatural derivatives of lipid A were synthesized with different number, location, and chain length of acyl groups and their influence on the biological activities has been accumulated. ${ }^{43), 55)-60)} \mathrm{Ad}-$ ditional structural modification of lipid A can also be possible: either one or even both of the phosphate groups can synthetically be substituted by other acidic groups without loosing the original biological activity. ${ }^{43), 61)}$ 1-O-Phosphonooxyethyl (PE) analogues (15 and 16) among such products, in particular, were quite valuable since substitution of the glycosyl phosphate groups improved the stability of the products and hence their synthesis and purification were much easier than the natural type compounds. ${ }^{43)}$ This merit was utilized in the synthesis of pure tritium-labeled bioactive lipid A derivatives (15a and 16a) with high specific radioactivity. ${ }^{62)}$ The PE analogues (15 and 16) show indistinguishable activity with those of natural type biosynthetic precursor and mature E. coli lipid A (13 and $\mathbf{1 4}$ ), respectively: the former was antagonistic while the latter endotoxic. ${ }^{61)}$ These labeled compounds were subjected to experiments aiming at direct identification of lipid A-binding proteins on animal cell but the attempt failed to obtain clear-cut informationn. ${ }^{62)}$ The labeled compounds were utilized in analyzing the interaction of lipid A and its binding receptor complex discovered after five years as described later. 

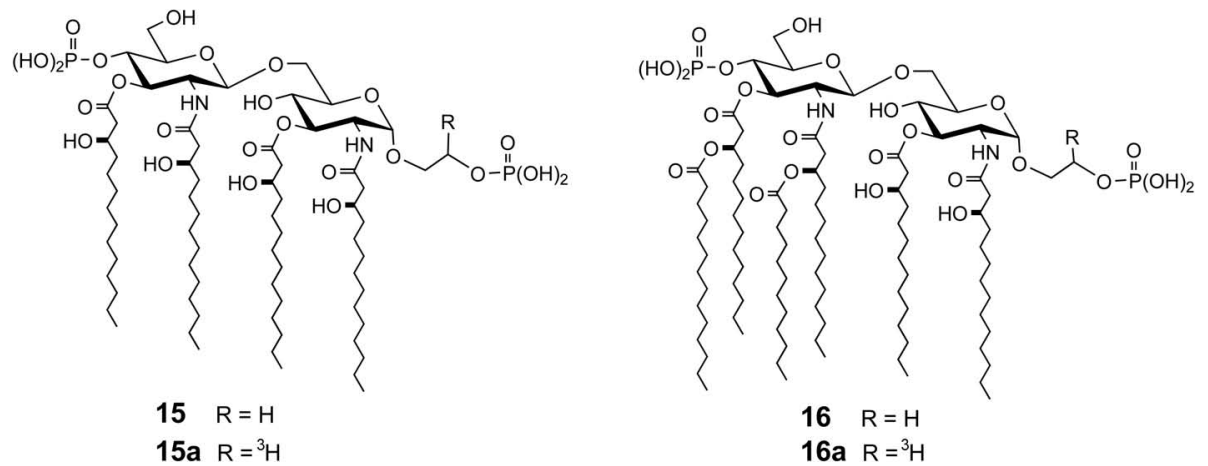

Fig. 8. Chemical structures of phosphonooxyethyl analogues (15 and 16) of lipid A.

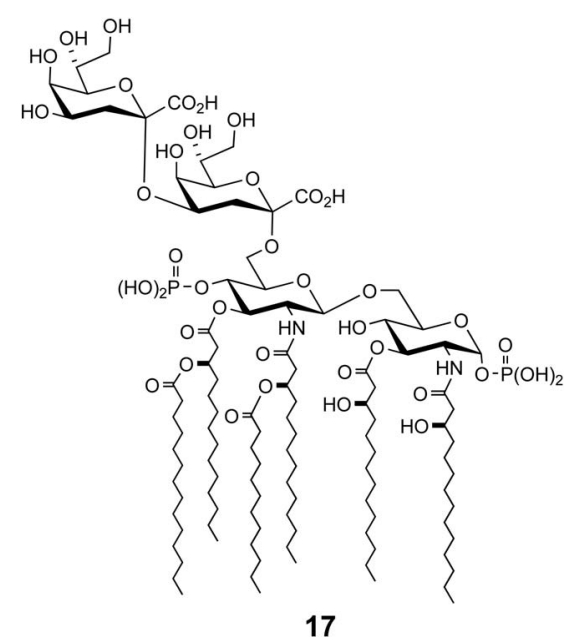

Fig. 9. Chemical structure of E. coli Re LPS (17).

\section{Chemical synthesis of Re-type lipopolysaccharide}

After substantial knowledge has been accumulated on the structure-activity relationship of the lipid A residue, our next attempt was directed toward synthesis of more complex structure present in natural LPS. Though lipid A was undoubtedly concluded to be a structural moiety responsible for exertion of endotoxic activity, this glycolipid is always accompanied with a covalently bound saccharide chain when present on bacterial cell surface. Since the roles of the additional saccharide parts were not precisely studied yet, we decided to start total chemical synthesis of an LPS molecule actually present on living bacterial cell wall. The target selected was the LPS produced by E. coli Re mutant. This mutant has deep deficiency in the biosynthetic system and pro- duces LPS lacking most of the saccharide chain but a disaccharide linked to the 6'-positions of lipid A. This molecule $\mathbf{1 7}$, whose structure was previously determined by us, ${ }^{63)}$ provides with a good model for elucidation of the role of additional sugar units linked to lipid A on the biological activity.

Even though $\mathbf{1 7}$ is the smallest member of the LPS family, its complex architecture and the presence of the unique eight carbon acidic sugar, 3-deoxy-Dmanno-octulosonic acid (formerly called 2-keto-3deoxyocutonic acid and thus traditionally abbreviated Kdo) makes the synthesis a real challenge for chemists. The ketosidic linkage of Kdo is quite labile to acidic treatments, which was the reason enabled Westphal and Lüderitz to discover liberation of lipid A by mild acid hydrolysis of LPS. The presence of both base-labile acyl groups and the acid-labile glycosyl phosphate and Kdo in the target molecule required elaboration of mild reaction conditions for most transformation steps. An efficient method for regio- and $\alpha$-selective formation of ketosidic linkages of Kdo had also to be established. Selective protection and deprotection during synthetic steps were additional important issues.

The synthetic route to $\mathbf{1 7}$ was so designed that we can utilize the knowledge accumulated through our synthetic works on lipid A. ${ }^{47)}{ }^{49)}$ Thus, the two Kdo units were introduced stepwise to a glucosamine disaccharide portion corresponding to lipid A that already had all acyl groups at the required positions. The basic strategy was also maintained where the glycosyl phosphate was introduced at the last stage just before the final hydrogenolytic deprotection, as in the case of lipid A synthesis. Since the presence of a protected 4'-phosphate proved to inhibit coupling of the Kdo residue at the 6'-hydroxy group of the dis- 
<smiles>O=C(O[C@@H]1OC(c2ccccc2)C2OCC(O2)C1[N+](=O)[O-])C(Cl)(Cl)Cl</smiles>

18

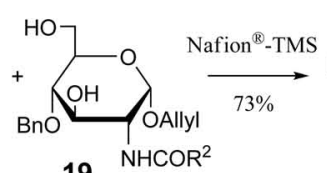

19

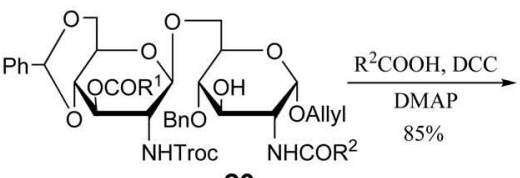

20
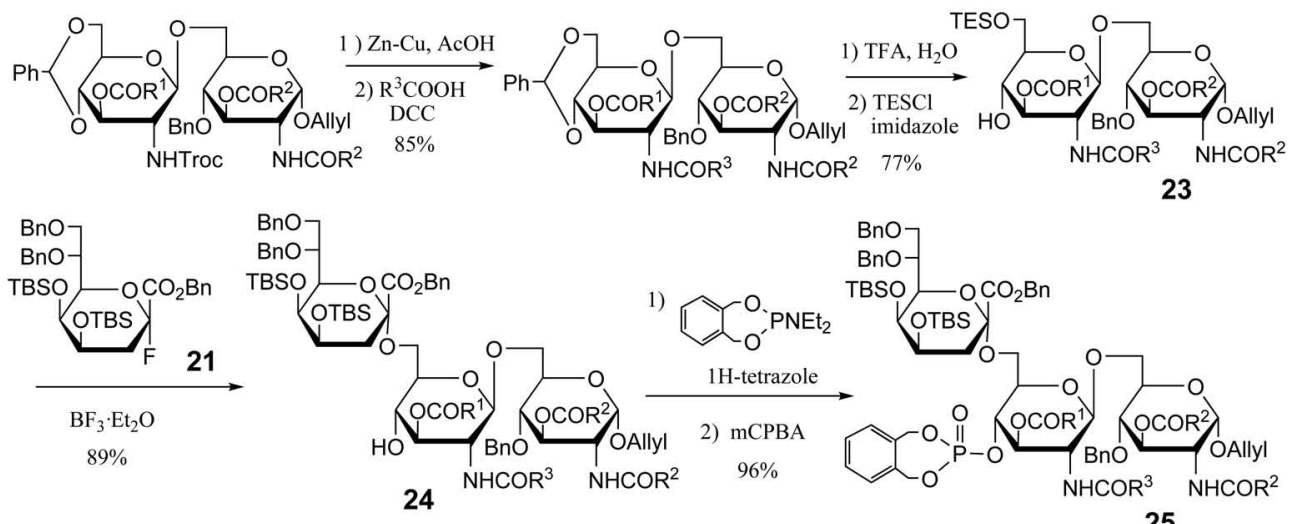

24
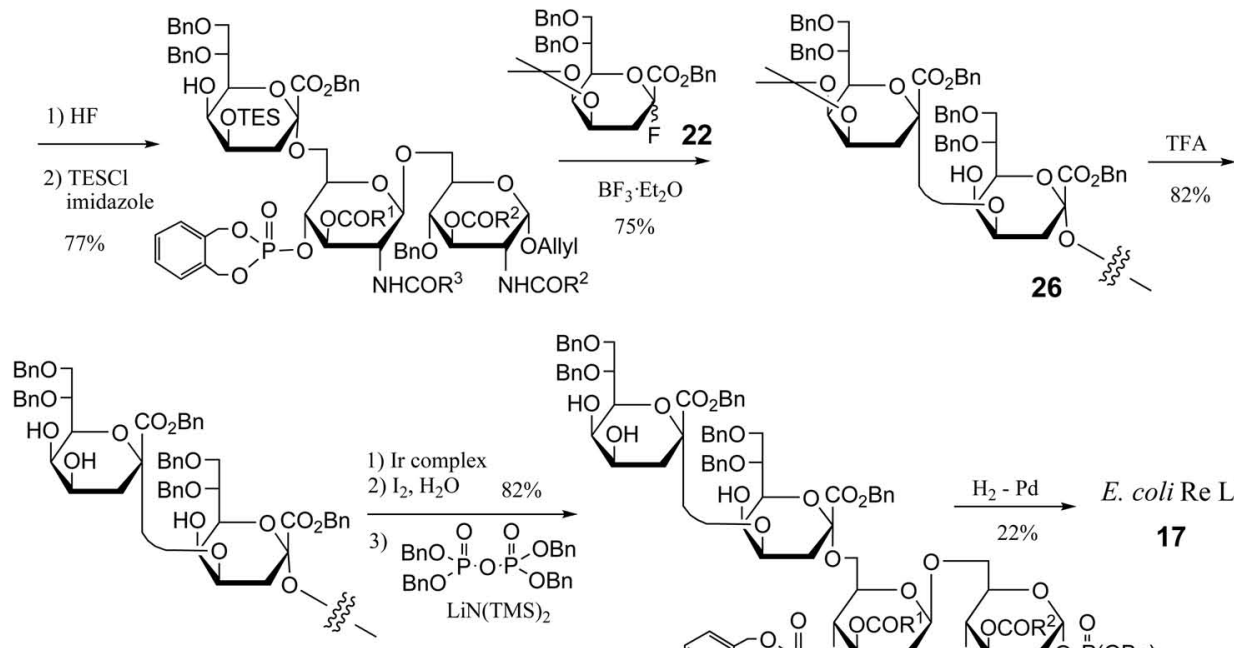

$\mathrm{BnO}_{7}$

$\mathrm{BnO}-1-2 \mathrm{O}^{-3 n}$

$\mathrm{HO}$

$\mathrm{OH} Y \mathrm{BnO}$
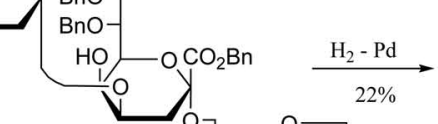

E. coli Re LPS

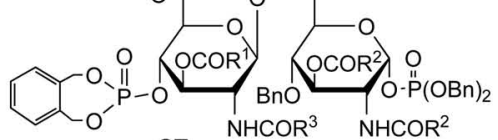

27

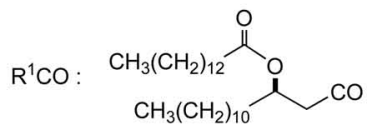

TES : triethylsilyl

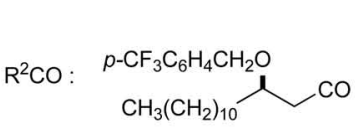

$\mathrm{R}^{3} \mathrm{CO}:$

Fig. 10. Synthetic route to E. coli Re LPS (17).

accharide, the phosphate on the 4'-position was introduced after the coupling of the first Kdo with the glucosamine disaccharide. ${ }^{64)}$

Coupling of 4,6-O-benzylidene- $N$-Troc-glucosamine trichloroacetimidate $(\mathbf{1 8})$ with another glucosamine unit (19) having free 3- and 6-hydroxy groups resulted in the selective formation of the desired $\beta(1-6)$ glucosamine disaccharide (20), to which the acyl groups at the $3-\mathrm{O}$ - and 2'- $\mathrm{N}$-positions were then introduced stepwise. After the removal of the benzylidene-protecting group, the primary 6'-hydroxy group was converted into triethylsilyl ether for selective activation for the subsequent reaction with a Kdo donor. ${ }^{64)}$ 
Formation of $\alpha$-linkages of pyranosidic Kdo units was effected using suitably protected Kdo fluorides as donors. A new route was elaborated in our previous work for the construction of the eightcarbon skeleton of Kdo starting from a D-mannose derivative and a dithioacetal of glyoxylic acid. ${ }^{65), 66)}$ Two Kdo fluorides $\mathbf{2 1}$ and $\mathbf{2 2}$ were prepared via this route with some modifications according to van Boom et al. ${ }^{67)}$ Lewis acid-catalyzed reactions of Kdo fluorides with hydroxy groups activated as silyl ethers proceeded smoothly in good yields. ${ }^{68)} \mathrm{Kdo}$ donors having sterically demanding protecting groups such as isopropylidene or TBS groups on the 4- and 5 -positions, gave satisfactorily high $\alpha$-selectivity because the access of the glycosyl acceptor from the $\beta$ face of the Kdo donor is hindered. ${ }^{64), 68)}$

Coupling of the fluoride $\mathbf{2 1}$ and the lipid A part disaccharide $\mathbf{2 3}$ devoid of the 4'-phosphate proceeded smoothly to give the desired trisaccharide $\mathbf{2 4}$ containing $\alpha$-linked Kdo in excellent stereoselectivity and high yield. The free 4'-hydroxy group of $\mathbf{2 4}$ was then phosphorylated by the phosphoramidite method to afford a bisphosphorylated trisaccharide $\mathbf{2 5}$, whose both TBS groups were then removed and the 4". hydroxy group of the product selectively converted to its triethylsilyl ether. To this position the second Kdo was introduced by using the 4,5-O-isopropylidene protected Kdo fluoride 22. The reaction successfully proceeded again with perfect $\alpha$-selectivity to complete the tetrasaccharide backbone of Re LPS. The TBS-protected donor $\mathbf{2 1}$ gave lower yield when used at this step probably because of the too large steric demand of the TBS groups. The isopropylidene groups of the resultant tetrasaccharide derivative $\mathbf{2 6}$ were removed under mild acidic conditions, where acid labile ketosidic linkages were retained. After cleavage of the allyl glycoside, the free glycosidic position was selectively phosphorylated to give the desired protected Re LPS 27, which was subjected to the final hydrogenolytic deprotection to give the first synthetic Re LPS 17.64)

From the result of biological tests of the synthetic compound, the effect of the Kdo residues was clearly shown to enhance the potency of lipid A in activation of the innate immune system. For example, synthetic Re LPS 17 showed higher IL-6 inducing activity than synthetic E. coli lipid A. ${ }^{64)}$ By appropriate modifications of the above synthetic route to $\mathbf{1 7}$, a compound with one Kdo linked to lipid A was also prepared. More recently, chemical synthesis was achieved of further Kdo-containing lipid A derivatives corresponding to partial structures of Helicobacter pylori LPS. ${ }^{69}$ Comparison of the biological activity of such synthetic compounds gave further proof of the effect of the Kdo residues.

\section{Concluding remarks}

Through the long-termed intensive research on the activation of the immunological system of higher animals by bacterial cell components, the overall picture of innate immunity has been gradually unveiled. Innate immunity is the first line basic defense system of animals against invading microorganisms. When we started our synthetic works on PGN and LPS aiming at the characterization of essential structural elements of these bacterial high molecular components, we thought it quite rational that typical and vital components of microbes are recognized as the sign of invasion and trigger the defense system of hosts, though the general idea of innate immunity was not established yet. When the first synthetic specimen of MDP and lipid A became available, their biological activities were tested by in vivo systems for evaluation of leukocyte migration and antibody level in guinea pigs, pyrogenicity in rabbits, lethal toxicity in mice and so on. Later, activities were more quantitatively determined by measuring the amounts of individual cytokines secreted from cells by using the ELISA technique. Various cell lines including cultured human cells also became available, which led to the discovery of the antagonistic activity of $\mathbf{1 3}$ and $\mathbf{1 5}$ as described above.

Several proteins such as LPS-binding protein (LBP) and CD14 that bind to LPS and lipid A have been identified in sera or cell surfaces of higher animals. ${ }^{70), 71)}$ However, they are either soluble or cell surface proteins that lack the intracellular domains essential for the transfer of signals into cells. After the discovery of a membrane protein named Toll, ${ }^{72}$ ) which participates in the defense of insects against fungi, in 1996, revolutionary advances were brought about in our understanding of innate immune receptors. Members of the mammalian Toll-like receptor (TLR) family were soon characterized by homology search. TLRs are membrane proteins sharing the same structural features of extracellular leucine-rich repeats and intracellular IL-1 receptor-like signaling 
domains. ${ }^{73)}$ The system of specific recognition of various microbial cell components by individual TLRs and signaling system thereafter are now well understood.4),74) TLR4 among them was proved to be the specific receptor for lipid A, a decisive evidence being obtained by the use of our synthetic pure lipid A specimen. ${ }^{75)}$ Miyake et al. then found that an additional protein named MD2 which is bound to TLR4 is essential for the recognition of lipid A by the latter. ${ }^{76)}$ They further analyzed the mechanism of lipid A recognition by TLR4-MD2 complex by the use of our synthetic radio-labeled derivatives of lipid A 16a and antagonistic precursor 15a. ${ }^{77)-79)}$ More recently, direct crystallographic structure was obtained for a complex of our synthetic lipid A precursor with MD2 ${ }^{80}$ ) and then for a complex of other artificial lipid A antagonist with TLR4-MD2 by other independent group. ${ }^{81)}$ Dimeric structure of TLR-MD2-LPS ternary complex was then determined by X-ray crystallographic analysis as well to explain the receptor activation mechanism. ${ }^{82}$ The precise molecular mechanism of lipid A recognition as a key bacterial component is being unveiled from various directions.

It is a rational and sophisticated strategy of higher animals to use ubiquitous cell components essential for the survival of bacteria. Bacteria can not escape this defense system because they are neither alive without these structural units of their cells nor allowed to basically modify the structure of their essential elements. Our synthetic works described in this article have promoted general understanding of this highly important innate immune system by giving concrete molecular basis of pure key substrate molecules and thus clear-cut results in biological investigations. Various physicochemical investigations have also become possible by the use of pure molecules, ${ }^{83)}$ though not described in this article, new routes having been opened to investigate interaction and molecular behavior of the key molecules, lipid A and LPS, on lipid membranes. ${ }^{84), 85)}$ Such approaches are expected to give information on the very early stage of innate immune processes. Quite other direction of researches has also now emerging on the TLR systems of animals other than mammals by several research groups including ourselves. ${ }^{86)}$ Such approaches may also give new information from evolutional aspects and help understand the origin and significance of our own defense system of innate immunity.

\section{References}

1) Stewart-Tull, D. E. S. (1985) Immunopotentiating activity of peptidoglycan and surface polymers. In Immunology of Bacterial Cell Envelope (eds. Stewart-Tull, D. E. S. and Davies, M.). JohnWiley \& Sons, Chichester, UK, pp. 47-89.

2) Rietschel, E. Th. and Westphal, O. (1999) Endotoxin: Historical perspectives. In Endotoxin in Health and Disease (eds. Brade, H., Opal, S. M., Vogel, S. N. and Morrison, D. C.). Marcel Dekker, New York, pp. 1-31.

3) Kotani, S., Narita, T., Stewart-Tull, D. E. S., Shimono, T., Watanabe, Y., Kato, K. et al. (1975) Immunoadjuvant activities of cell walls and their water-soluble fractions prepared from gram-positive bacteria. Biken J. 18, 77-92.

4) Akira, S. (2009) Innate immunity to pathogens: diversity in receptors for microbial recognition. Immunol. Rev. 227, 5-8.

5) Ghuysen, J. M. and Hackenbeck, B. (1994) New Comprehensive Biochemistry. Elsevier Biomedical, Amsterdam.

6) Vollmer, W. and Born, P. (2009) Bacterial cell envelope peptidoglycan. In Microbial Glycobiology (ed. Moran, A. P). Academic Press, London, pp. 15-28.

7) Kotani, S., Watanabe, Y., Shimono, T., Narita, T., Kato, K., Stewart-Tull, D. E. S. et al. (1975) Immunoadjuvant activities of cell walls, their watersoluble fractions and peptidoglycan subunits, prepared from various gram-positive bacteria, and of synthetic $N$-acetylmuramyl peptides. Z. Immun.Forsch. 149, 302-319.

8) Kusumoto, S., Tarumi, Y., Ikenaka, K. and Shiba, T. (1976) Chemical synthesis of $N$-acetylmuramyl peptides with partial structures of bacterial cell wall and their analogs in relation to immunoadjuvant activities. Bull. Chem. Soc. Jpn. 49, 533-539.

9) Ellouz, F., Adam, A., Ciorubaru, R. and Lederer, E. (1974) Minimal structural requirements for adjuvant activity of bacterial peptidoglycan derivatives. Biochim. Biophys. Res. Commun. 59, $1317-$ 1325 .

10) Merser, C., Sinay, P. and Adam, A. (1975) Total synthesis and adjuvant activity of bacterial peptidoglycan derivatives. Biochem. Biophys. Res. Commun. 66, 1316-1322.

11) Kotani, S., Watanabe, Y., Kinoshita, F., Morisaki, I., Kato, K., Shiba, T. et al. (1977) The effect of replacement of L-alanine residue by glycine, L-serine or D-alanine in an $\mathrm{N}$-acetylmuramyl-L-alanyl-Disoglutamine on immunoadjuvancies of molecules. Biken J. 20, 39-45.

12) Kusumoto, S., Ikenaka, K. and Shiba, T. (1979) Syntheses of several muramyl peptides in relation to chemical structures of less immunoadjuvant bacterial cell walls. Bull. Chem. Soc. Jpn. 52, 16651671.

13) Kusumoto, S., Ikenaka, K. and Shiba, T. (1979) Preparation of $N$-acetylmuramyl-L-[U_ $\left.{ }^{14} \mathrm{C}\right]$ alanylD-isoglutamine via a novel synthetic route. Bull. Chem. Soc. Jpn. 52, 1177-1181. 
14) Kusumoto, S., Yamamoto, K. and Shiba, T. (1978) Synthesis of $N$-acetyl- $\beta$-D-glucosaminyl-(1-4)- $N$ acetylmuramyl-L-alanyl-D-isoglutamine. Tetrahedron Lett. 19, 4407-4410.

15) Tsujimoto, M., Kinoshita, F., Okunaga, T., Kotani, S., Kusumoto, S., Yamamoto, K. et al. (1979) Higher immunoadjuvant activities of $N$-acetyl- $\beta$-D-glucosaminyl-(1-4)- $N$-acetylmuramyl-L-alanyl-D-isoglutamine in comparison with $\mathrm{N}$-acetylmuramyl-Lalanyl-D-isoglutamine. Microbiol. Immumol. 23, 933-936.

16) Inamura, S., Fukase, K. and Kusumoto, S. (2001) Synthetic study of peptidoglycan partial structures. Synthesis of tetrasaccharide and octasaccharide fragments. Tetrahedron Lett. 42, 76137616.

17) Inamura, S., Fujimoto, Y., Kawasaki, A., Shiokawa, Z., Woelk, E., Heine, H. et al. (2006) Synthesis of peptidoglycan fragments and evaluation of their biological activity. Org. Biomol. Chem. 4, 232-242.

18) Weidemann, B. Schletter, J., Dziarski, R., Kusumoto, S., Stelter, F., Rietschel, E. Th. et al. (1997) Specific binding of soluble peptidoglycan and muramyldipeptide to CD14 on human monocytes. Infect. Immun. 65, 858-864.

19) Inohara, N., Ogura, Y., Fontalba, A., Gutierrez, O., Pons, F., Crespo, J. et al. (2003) Host recognition of bacterial muramyl dipeptide mediated through NOD2. J. Biol. Chem. 278, 5509-5512.

20) Chamaillard, M., Hashimoto, M., Horie, Y., Masumoto, J., Qiu, S., Saab, L. et al. (2003) An essential role for NOD1 in host recognition of bacterial peptidoglycan containing diaminopimelic acid. Nat. Immunol. 4, 652-654.

21) Kawasaki, A., Karasudani, Y., Otsuka, Y., Hasegawa, M., Inohara, N., Fujimoto, Y. et al. (2008) Synthesis of diaminopimelic acid containing peptidoglycan fragments and tracheal cytotoxin (TCT) and investigation of their biological functions. Chem. Eur. J. 14, 10318-10330.

22) Schleifer, K. H. and Kandler, O. (1972) Peptidoglycan types of bacterial cell walls and their taxonomic implications. Bacteriol. Rev. 36, 407-477.

23) Inohara, N., Chmaillard, M., McDonald, C. and Nuñez, G. (2005) NOD-LRR proteins: Role in host-microbial interactions and inflammatory disease. Ann. Rev. Biochem. 74, 355-383.

24) Hasegawa, M., Yang, K., Hashimoto, M., Park, J.-H., Kim, Y.-G., Fujimoto, Y. et al. (2006) Differential release and distribution of Nod1 and Nod2 immunostimulatory molecules among bacterial species and environments. J. Biol. Chem. 281, 2905429063.

25) Pfeiffer, R. Z. (1892) Untersuchengen über das Choleragift. Hygiene 11, 393-412.

26) Westphal, O., Lüderitz, O. and Bister, F. (1952) Über die Extraction von Bakterien mit Phenol/Wasser. Z. Naturforsch. 7, 148-155.

27) Westphal, O. and Lüderitz, O. (1954) Chemische Erforschung von Lipopolysacchariden gram-negativer Bakterien. Angew. Chemie 66, 407-417.

28) Lüderitz, O., Galanos, C., Lehmann, V., Nurminen,
M., Rietschel, E. Th., Rosenfelder, G. et al. (1973) Lipid A: Chemical structure and biological activity. J. Infect. Dis. 128 (Suppl.), 17-29.

29) Rietschel, E. Th., Sydorczyk, Z., Zähringer, U., Wollenweber, H.-W. and Lüderitz, O. (1983) Analysis of primary structure of lipid A. In Bacterial Lipopolysaccharide (eds. Anderson, L. and Unger, F. M.). ACS Symposium Series 231, American Chemical Society, Washington DC, pp. 195-218.

30) Inage, M., Chaki, H., Imoto, M., Shimamoto, T., Kusumoto, S. and Shiba, T. (1983) Synthetic approach to lipid A: Preparation of phosphorylated disaccharides containing $(R)$-3-hydroxyacyl and $(R)$-3-acyloxyacyl groups. Tetrahedron Lett. 24, 2011-2014.

31) Kusumoto, S., Inage, M., Chaki, H., Imoto, M., Shimamoto, T. and Shiba, T. (1983) Chemical synthesis of lipid A for the elucidation of structure-activity relationship. In Bacterial Lipopolysaccharide (eds. Anderson, L. and Unger, F. M.). ACS Symposium Series 231, American Chemical Society, Washington DC, pp. 237-254.

32) Lüderitz, O., Tanamoto, K., Galanos, C., Westphal, O., Zähringer, U., Rietschel, E. Th. et al. (1983) Structural principles of lipopolysaccharides and biological properties of synthetic partial structures. In Bacterial Lipopolysaccharide (eds. Anderson, L. and Unger, F. M.). ACS Symposium Series 231, American Chemical Society, Washington DC, pp. $3-17$.

33) Imoto, M., Kusumoto, S., Shiba, T., Naoki, H., Iwashita, T., Rietschel, E. Th. et al. (1983) Chemical structure of E. coli lipid A: Linkage site of acyl groups in the disaccharide backbone. Tetrahedron Lett. 24, 4017-4020.

34) Imoto, M., Yoshimura, H., Kusumoto, S. and Shiba, T. (1984) Total synthesis of lipid A, active principle of bacterial endotoxin. Proc. Japan Acad., Ser. B 60, 285-288.

35) Imoto, M., Kusumoto, S., Shiba, T., Rietschel, E. Th., Galanos, C. and Lüderitz, O. (1985) Chemical structure of Escherichia coli lipid A. Tetrahedron Lett. 26, 907-908.

36) Imoto, M., Yoshimura, H., Yamamoto, M., Shimamoto, T., Kusumoto, S. and Shiba, T. (1984) Chemical synthesis of phosphorylated tetraacyl disaccharide corresponding to a biosynthetic precursor of lipid A. Tetrahedron Lett. 25, 2667-2670.

37) Imoto, M., Yoshimura, H., Yamamoto, M., Shimamoto, T., Kusumoto, S. and Shiba, T. (1987) Chemical synthesis of a biosynthetic precursor of lipid A with a phosphorylated tetraacyl disaccharide structure. Bull. Chem. Soc. Jpn. 60, 2197-2204.

38) Imoto, M., Yoshimura, H., Shimamoto, T., Sakaguchi, N., Kusumoto, S. and Shiba, T. (1987) Total synthesis of Escherichia coli lipid A, the endotoxically active principle of cell-surface lipopolysaccharide. Bull. Chem. Soc. Jpn. 60, 2205-2214.

39) Galanos, C., Lehman, V., Lüderitz, O., Rietschel, E. Th., Westphal, O., Brade, H. et al. (1984) Endotoxic properties of chemically synthesized lipid A part structures - comparison of synthetic lipid A 
precursor and synthetic analogues with biosynthetic lipid A precursor and free lipid A. Eur. J. Biochem. 140, 221-227.

40) Takada, H., Kotani, S., Tsujimoto, M., Ogawa, T., Takahashi, I., Harada, K. et al. (1985) Immunopharmacological activities of a synthetic counterpart of a biosynthetic lipid A precursor molecule and of its analogs. Infect. Immun. 48, 219-227.

41) Galanos, C., Lüderitz, O., Rietschel, E. Th., Westphal, O., Brade, H., Brade, L. et al. (1985) Synthetic and natural Escherichia coli free lipid A express identical endotoxic activities. Eur. J. Biochem. 148, 1-5.

42) Kotani, S., Takada, H., Tsujimoto, M., Ogawa, T., Takahashi, I., Ikeda, T. et al. (1985) Synthetic lipid A with endotoxic and related biological activities comparable to those of a natural lipid A from an Escherichia coli Re-mutant. Infect. Immun. 49, 225-237.

43) Liu, W.-C., Oikawa, M., Fukase, K., Suda, Y. and Kusumoto, S. (1999) A divergent synthesis of lipid $\mathrm{A}$ and its chemically stable unnatural analogues. Bull. Chem. Soc. Jpn. 72, 1377-1385.

44) Takada, H. and Kotani, S. (1989) Structural requirements of lipid A for endotoxicity and other biological activities. CRC Critical Rev. Microbiol. 16, $477-523$

45) Takada, H. and Kotani, S. (1992) Structure-function relationships of lipid A. In Bacterial Endotoxic Lipopolysaccharides. Vol. I: Molecular Biochemistry and Cellular Biology (eds. Morrison, D. C. and Ryan, J. L.). CRC Press, Boca Raton, USA, pp. $43-65$.

46) Kusumoto, S., Fukase, K., Fukase, Y., Kataoka, M., Yoshizaki, H., Sato, K. et al. (2003) Structural basis for endotoxic and antagonistic activities: investigation with novel synthetic lipid A analogs. J. Endotoxin Res. 9, 361-366.

47) Kusumoto, S., Fukase K. and Fujimoto, Y. (2007) Synthesis of lipopolysaccharide, peptidoglycan and lipoteichoic acid fragments. In Comprehensive Glycoscience. Vol. 1 (ed. Kamerling J. P.). Elsevier, Amsterdam, pp. 685-711.

48) Kusumoto, S., Fukase, K. and Fujimoto, Y. (2009) Chemical synthesis of bacterial lipid A. In Microbial Glycobiology, Structures, Relevance and Applications (ed. Moran, A. P.). Academic Press, London, pp. 415-427.

49) Kusumoto, S., Hashimoto, M. and Kawahara, K. (2009) Structure and synthesis of lipid A. In Lipid A in Cancer Therapy (ed. Jeaninn, J.-F.). Advances in Experimental Medicine and Biology. Vol. 667, Landes Bioscience, New York, pp. 5-23.

50) Flad, H.-D., Loppnow, H., Feist, W., Wang, M.-H., Brade, H., Kusumoto, S. et al. (1989) Interleukin 1 and tumor necrosis factor: Studies on the induction by lipopolysaccharide partial structures. Lymphokine Research 8, 235-238.

51) Wang, M.-H., Feist, W., Herzbeck, H., Brade, H., Kusumoto, S., Rietschel, E. Th. et al. (1990) Suppressive effect of lipid A partial structures on lipopolysaccaride or lipid A-induced release of inter- leukin 1 by human monocytes. FEMS Microbiol. Immunol. 64, 179-186.

52) Salimath, P. V., Weckesser, J., Strittmater, W. and Meyer, H. (1983) Structural studies on the nontoxic lipid A from Rhodopseudomonas sphaeroides ATCC 17023. Eur. J. Biochem. 136, 195-200.

53) Takayama, K., Qureshi, N., Beutler, B. and Kirkland, T. N. (1989) Diphosphoryl lipid A from Rhodopseudomonas sphaeroides ATCC 1702 blocks induction of cachectin in macrophage by lipopolysaccharide. Infect. Immun. 57, 1336-1338.

54) Christ, W. J., Asano, O., Robidoux, A. L., Perez, M., Wang, Y., Dubuc, G. R. et al. (1994) E5531, a pure endotoxin antagonist of high potency. Science 268, 80-83.

55) Rossignol, D. P., Hawkins, L. D., Christ, W. J., Kobayashi, S., Kawata, T., Lynn, M. et al. (1999) Synthetic endotoxin antagonist. In Endotoxin in Health and Disease (eds. Brade, H., Opal, S. M., Vogel, S. N. and Morrison, D. C.). Marcel Dekker, New York, pp. 699-717.

56) Kusama, T., Soga, T., Shioya, E., Nakayama, K., Nakajima, H., Osada, Y. et al. (1990) Synthesis and antitumor activity of lipid A analogs having a phosphonooxyethyl group with $\alpha$ - or $\beta$-configuration at position 1. Chem. Pharm. Bull. 38, 33663372 .

57) Kusama, T., Soga, T., Ono, Y., Kumazawa, E., Shioya, E., Osada, Y. et al. (1991) Synthesis and biological activities of analogs of a lipid A biosynthetic precursor: 1-O-phosphonooxyethyl-4'-O-phosphono-disaccharides with $(R)$-3-hydroxytetradecanoyl or tetradecanoyl groups at positions 2, 3, 2' and 3'. Chem. Pharm. Bull. 39, 1994-1999.

58) Fukase, Y., Fujimoto, Y., Adachi, Y., Suda, Y. Kusumoto, S. and Fukase, K. (2008) Synthesis of Rubrivivax gelatinosus lipid A and analogues for investigation of the structural basis for immunostimulating and inhibitory activities. Bull. Chem. Soc. Jpn. 81, 796-819.

59) Sakai, Y., Oikawa, M., Yoshizaki, H., Ogawa, T., Suda, Y., Fukase, K. et al. (2000) Synthesis of Helicobacter pylori lipid A and its analogue using $p$-(trifluoromethyl)benzyl protecting group. Tetrahedron Lett. 41, 6843-6847.

60) Fukase, K., Fukase, Y., Oikawa, M., Liu, W.-C., Suda, Y. and Kusumoto, S. (1998) Divergent synthesis and biological activities of lipid A analogues of shorter acyl chains. Tetrahedron 54, 4033-4050.

61) Ulmer, A. J., Heine, H., Feist, W., Kusumoto, S. Kusama, T., Brade, H. et al. (1992) Biologicalactivity of synthetic phosphonooxyethyl analogs of lipid-A and lipid-A partial structures. Infect. Immun. 60, 3309-3314.

62) Fukase, K., Kirikae, T., Kirikae, F., Liu, W.-C., Oikawa, M., Suda, Y. et al. (2001) Synthesis of $\left[{ }^{3} \mathrm{H}\right]$-labeled bioactive lipid A analogs and their use for detection of lipid A-binding proteins on murine macrophages. Bull. Chem. Soc. Jpn. 74, 21892197.

63) Zähringer, U., Lindner, B., Seydel, U., Rietschel, E. Th., Naoki, H., Unger, F. M. et al. (1985) Struc- 
ture of de-O-acylated lipopolysaccharide from the Escherichia coli Re mutant strain F515. Tetrahedron Lett. 26, 6321-6324.

64) Yoshizaki, H., Fukuda, N., Sato, K., Oikawa, M., Fukase, K., Suda, Y. et al. (2001) First total synthesis of the Re-type lipopolysaccharide. Angew. Chem. Int. Ed. 40, 1475-1480.

65) Imoto, M., Kusunose, N., Matsuura, Y., Kusumoto, S. and Shiba, T. (1987) Preparaton of novel pyranosyl fluorides of 3-deoxy-D-manno-2-octulosonic acid (KDO) feasible for synthesis of KDO $\alpha$-glycosides. Tetrahedron Lett. 28, 6277-6280.

66) Imoto, M., Kusumoto, S. and Shiba, T. (1987) A new synthesis of 3-deoxy-D-manno-2-octulosonic acid (KDO) from D-mannose. Tetrahedron Lett. 28, 6235-6238.

67) van der Klein, P. A. M., Boons, G. J. P. H., Veeneman, G. H., van der Marel, G. A. and van Boom, J. H. (1989) An efficient route to 3-deoxy-Dmanno-2-octulosonic acid (KDO) derivatives via a 1,4-cyclic sulfate approach. Tetrahedron Lett. 30, $5477-5480$.

68) Fukase, K., Kurosawa, M. and Kusumoto, S. (1994) Synthesis and purification by HPLC of des- $O$-acyl partial structures of Escherichia coli Re lipopolysaccharide. J. Endotoxin Res. 1, 149-163.

69) Fujimoto, Y., Iwata, M., Imakita, N., Shimoyama, A., Suda, Y., Kusumoto, S. et al. (2007) Synthesis of immunoregulatory Helicobacter pylori lipopolysaccharide partial structures. Tetrahedron Lett. 48, 6577-6581.

70) Ulevitch, R. J. and Tobias, P. S. (1995) Receptordependent mechanisms of cell stimulation by bacterial endotoxin. Annu. Rev. Immunol. 13, 437-457.

71) Takeda, K. (2009) The lipid A receptor. In Lipid A in Cancer Therapy (ed. Jeaninn, J.-F.). Advances in Experimental Medicine and Biology. Vol. 667, Landes Bioscience, New York, pp. 53-58.

72) Lemaitre, B., Nicolas, E., Michaut, L., Reichhart, J. M. and Hoffmann, J. A. (1996) The drosoventral regulatory gene cassette spätzle/Toll/cactus controls the potent antifungal response in Drosophila adults. Cell, 86, 973-983.

73) Akira, S. and Takeda, K. (2004) Toll-like receptor signalling. Nat. Rev. Immunol. 4, 499-511.

74) Kumar, H., Kawai, T. and Akira, S. (2009) Toll-like receptors and innate immunity. Biochem. Biophys. Res. Commun. 388, 621-625.

75) Lien, E., Means, T. K., Heine, H., Yoshimura, A., Kusumoto, S., Fukase, K. et al. (2000) Toll-like receptor 4 imparts ligand-specific recognition of bacterial lipopolysaccharide. J. Clinic. Invest. 105, 497-504.

76) Shimazu, R., Akashi, S., Ogata, Y., Nagai, Y., Fukudome, K., Miyake, K. et al. (1999) MD-2, a mole- cule that confers lipopolysaccharide responsiveness on Toll-like receptor 4. J. Exp. Med. 189, 17771782 .

77) Saitoh, S.-I., Akashi, S., Yamada, T., Tanimura, N. Kobayashi, M., Konno, K. et al. (2004) Lipid A antagonist, lipid $\mathrm{lVa}$, is distinct from lipid $\mathrm{A}$ in interaction with Toll-like receptor 4 (TLR4)-MD-2 and ligand-induced TLR4 oligomerization. Int. Immunol. 16, 961-969.

78) Kobayashi, M., Saitoh, S., Tanimura, N., Takahashi, K., Kawasaki, K., Nishijima, M. et al. (2006) Regulatory roles for MD-2 and TLR4 in ligand-induced receptor clustering. J. Immunol. 176, 6211-6218.

79) Saitoh, S.-I. and Miyake, K. (2006) Mechanism regulating cell surface expression and activation of Tolllike receptor 4 . The Chemical Record 6, 311-319.

80) Ohto, U., Fukase, K., Miyake, K. and Satow, Y. (2007) Crystal structures of human MD-2 and its complex with antiendotoxic lipid IVa. Science 316, 1632-1634.

81) Kim, H. M., Park, B. S., Kim, J.-I., Kim, S. E., Lee, J., Oh, S. C. et al. (2007) Crystal structure of the TLR4-MD-2 complex with bound endotoxin antagonist Eritoran. Cell 130, 906-917.

82) Park, B. S., Song, D. H., Kim, H. M., Choi, B. S., Lee, H. and Lee, J. O. (2009) The structural basis of lipopolysaccharide recognition by the TLR4-MD-2 complex. Nature 458, 1191-1195.

83) Seydel, U., Wiese, A., Schromm, A. B. and Brandenburg, K. (1999) A biophysical view on the function and activity of endotoxins. In Endotoxin in Health and Disease (eds. Brade, H., Opal, S. M., Vogel, S. N. and Morrison, D. C.). Marcel Dekker, New York, pp. 195-219.

84) Nomura, K., Inaba, T., Morigaki, K., Brandenburg, K., Seydel, U. and Kusumoto, S. (2008) Interaction of lipopolysaccharide and phospholipid in mixed membranes: Solid-state ${ }^{31} \mathrm{P}-\mathrm{NMR}$ spectroscopic and microscopic investigations. Biophysical J. 95, 12261238.

85) Nomura, K., Maeda, M., Sugase, K. and Kusumoto, S. (2010) Lipopolysaccharide induces raft domain expansion in membrane composed of a phospholipidcholesterol-sphingomyelin ternary system. Innate Immun. 16, in press and references cited therein.

86) Sasaki, N., Ogasawara, M., Sekiguchi, T., Kusumoto, S. and Satake, H. (2009) Toll-like receptors of the ascidian Ciona intestinalis. Protoypes with hybrid functionalities of vertebrate Toll-like receptors. J. Biol. Chem. 284, 27336-27343 and references cited therein.

(Received Jan. 8, 2010; accepted Mar. 3, 2010) 


\section{Profiles}

Shoichi Kusumoto was born in 1940 and received his B.S. degree from Osaka University in 1963. He then joined the Faculty of Osaka City University as a research associate. After receiving his Ph.D., he spent two years at German Cancer Research Center (Prof. Erich Hecker), Heidelberg, as a Research Fellow of Alexander von Humboldt Foundation. In 1972, he moved to Osaka University and joined the research group of Prof. Tetsuo Shiba, where he started his chemical and functional studies on biologically active glycoconjugates. He was promoted to professor of organic chemistry in the same university in 1988. His research has been mainly focused on the structural analysis, synthesis, and biological functions of bacterial glycoconjugates. Through the systematic works of his group, the concept was established that the immunostimulating potencies

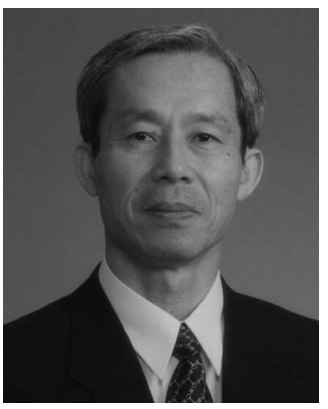
of bacterial cell surface complex components are attributed to smaller definite molecular species which are now recognized as typical triggers of our innate immune system as described in the present review article. Since April 2004, he is the director of Suntory Institute for Bioorganic Research, Osaka. For his scientific achievements, he received International Society of Immunopharmacology Award in 1983, Chemical Society of Japan Award in 1999, and The F. B. Bang Award of International Endotoxin Society in 2004.

Koichi Fukase was born in Okayama in 1960. He received his B.A. in 1982 and Ph.D. in 1987 from Osaka University under the direction of Professor Tetsuo Shiba. After receiving a fellowship of the Japan Society for the Promotion of Science for Japanese Junior Scientists for one year, he was appointed as Research Associate of Dr. Kusumoto's group at Osaka University in 1988. He was promoted to assistant professor (1996), associate professor (1998), and full professor (2004) at the same university. He was a recipient of The Chemical Society of Japan Award for Young Chemists in 1994. His research interest centers around chemical and biological study of oligosaccharides and glycoconjugates and chemical biology.

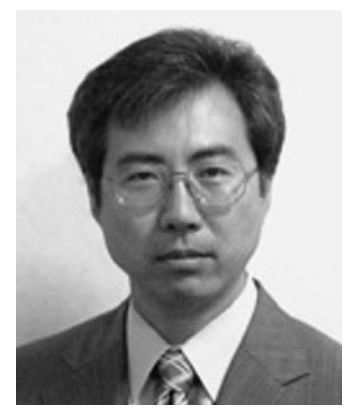

Tetsuo Shiba was born in 1924. After he received Ph.D. degree at Osaka University, he worked in NIH, USA, as a Visiting Scientist. In 1971, he was appointed as Professor, Department of Chemistry, Faculty of Science, Osaka University, and pursued many chemical achievements in structure and synthetic problems related to a diverse number of biologically active substances in the fields of marine amino acids, peptide antibiotics, and bacterial carbohydrates. Particularly his interests have been focused in elucidation based on chemical studies of the important activities of bacterial cell surface substances concerning human immunology. In 1975, the smallest structure, responsible for immunoadjuvant activities of the cell wall of Gram-positive bacteria was determined as $\mathrm{N}$-acetylmuramyl dipeptide. Furthermore, the entity of lipid A in

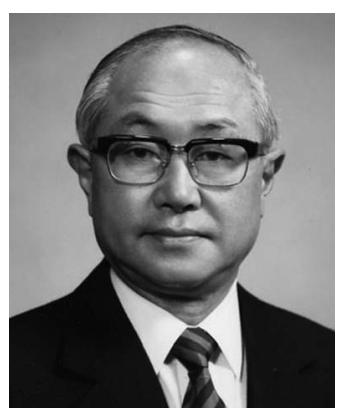
endotoxin of Gram-negative bacteria was also clarified for the first time as phosphorylated polyacyl disaccaride unequivocally. For these pioneering contributions in the field of bioorganic chemistry, he received the Award of the Chemical Society of Japan in 1982, and was designated as an Honorable Life Member of the International Endotoxin Society as well as Honorable Members of the Chemical Society of Japan and the Japanese Society for Carbohydrate Research. After he retired from Osaka University in 1988, he has been the Director of Peptide Institute, Protein Research Foundation. 